\title{
Influência das queimadas para a qualidade orgânica de duas áreas do cerrado tocantinense
}

Nos últimos anos, o cerrado brasileiro vem sofrendo fortes impactos devido a destruição da vegetação nativa. O presente artigo tem por objetivo expressar os resultados quali/quantitativos obtidos em um estudo sobre a influência do fogo na composição físico/química de dois solos em uma fazenda localizada no Município de Guaraí, Tocantins. Foram coletados dois tipos de solos que sofreram e que não sofreu queimada, recolhendo amostras da superfície e da profundeza de poços escavados para este fim. Estas amostras foram encaminhadas ao laboratório de solos para a realização das análises físicas e químicas dos solos. De modo geral, os resultados encontrados nos solos não apresentaram diferenças significantes, demonstrando que o fogo não alterou drasticamente a composição química destes solos. Apenas alguns elementos foram encontrados em menor quantidade nos solos queimados, e que alguns elementos se apresentaram em maior quantidade no solo queimado do que no solo que não sofreu a ação do fogo, como por exemplo, o Ferro que foi encontrado uma quantidade quase que dobrada no solo queimado. Diante das informações citadas a cima, conclui-se que é necessário realizar novos trabalhos com diferentes tipos de solos para testar a influência do fogo na composição química e física dos solos.

Palavras-chave: Fogo; Macronutrientes; Micronutrientes.

\section{Influence of fires on the organic quality of two areas in the Cerrado Tocantins}

\begin{abstract}
In recent years, the Brazilian savannah has suffered strong impacts caused by the destruction of native vegetation. This article aims to demonstrate the quali/quantitative results used in a study on the influence of fire on the physical / chemical composition of two soils on a farm located in the municipality of Guaraí, Tocantins. Two types of soils that suffered and did not suffer burns were collected, collection of surface samples and depths of wells dug for this purpose. These labels were sent to the solutions laboratory to carry out chemical and chemical analysis of the products. In general, the results found in soils that do not present significant differences, demonstrating that fire does not drastically alter the chemical composition of these soils. Only a few elements were found in the least number of burns, and some were found in greater quantity in the burnt soil than in the soil that did not suffer a fire action, for example, or the iron was found in an amount almost doubled in the burned soil. In view of the information mentioned above, conclude that it is necessary to carry out new works with different types of solutions to test the influence of fire on the chemical and physical composition of soils.
\end{abstract}

Keywords: Fire; Macronutrients; Micronutrients.

Topic: Ciência do Solo

Reviewed anonymously in the process of blind peer
Received: 02/11/2019

Approved: $11 / 02 / 2020$
Pedro Franco Noleto

Faculdade Guaraí, Brasil

http://lattes.cnpq.br/4414290483691490

franconoleto@yahoo.com.br

Plínio Costa Noleto

Faculdade Guaraí, Brasil

http://lattes.cnpq.br/4921224564665853

pliniocostanoleto@hotmail.com

Keila Ferreira de Sousa

Faculdade Guaraí, Brasil

http://lattes.cnpq.br/3201684428607508

http://orcid.org/0000-0003-2132-2693

keilaferreira35@hotmail.com.br

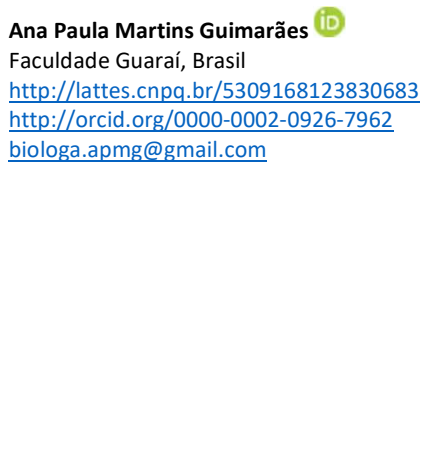

Referencing this:

NOLETO, P. F.; NOLETO, P. C.; SOUSA, K. F.; GUIMARÃES, A. P. M.. Influência das queimadas para a qualidade orgânica de duas áreas do cerrado tocantinense. Natural Resources, v.10, n.1, p.1-9, 2020. DOI: http://doi.org/10.6008/CBPC2237-9290.2020.001.0001 


\section{INTRODUÇÃO}

Nos últimos anos, o Cerrado brasileiro vem sofrendo fortes impactos devido a substituição da vegetação nativa por monoculturas de soja, cana-de-açúcar e pastagens (FERNANDES et al., 2011), mediados pelo aumento da população brasileira e consequentemente pelo forte antropização nos ambientes naturais do bioma. Fernandes et al. (2011), ressaltam ainda que, no passado esse bioma era definido por muitos como um solo infértil, porém, devido aos vários tratamentos de fertilização, na atualidade pode ser considerado a maior fronteira agrícola do planeta.

De acordo Brasil (2011), o cerrado tem como característica principal solos profundos (Latossolos) de coloração vermelha a amarela, que é pobre em nutrientes (cálcio, potássio, magnésio e micronutrientes), apresentando alta taxa de acidez e uma grande quantidade de alumínio, sendo o tipo de solo mais abrangente no bioma com uma área aproximada de $48 \%$, seguido dos solos arenosos $15 \%$ e dos pedregosos $15 \%$.

Além da perda da vegetação nativa, o cerrado também está passando por outros tipos de perturbações que podem levar a grandes distúrbios neste bioma, como por exemplo, as queimadas. Nas últimas décadas, as queimadas ganham destaque, principalmente nos períodos de estiagem, pois se trata de uma prática constantemente utilizada por pequenos produtores para a limpeza de pastagens, por se tratar de uma alternativa de baixo investimento financeiro (RHEINHEIMER et al., 2003; KLINK et al., 2005), no geral em longo prazo, os benefícios do uso dessa prática são bem menores se comparados aos prejuízos gerados (REDIN et al., 2011).

O fogo causa a degradação do solo contribuindo para diminuição de seus nutrientes e consequentemente da biomassa vegetal e da microfauna, interferindo no funcionamento do ecossistema, alterando as características físicas e químicas colaborando para a maior ocorrência de erosão devido à pouca cobertura superficial (KLINK et al., 2005; REDIN et al., 2011; JIMÉNEZ-CISNEROS, 2014).

Na região central do Brasil o fogo teve seu ápice de utilização, ainda no período colonial com a chegada dos primeiros colonizadores há cerca de 400 anos, que o utilizavam como ferramenta de cuidado do solo, sendo amplamente explorado pelos pequenos e grandes proprietários de terra deste período até a atualidade, colaborando para a grande incidência de fogo no território brasileiro (BRASIL, 2011). No Brasil os índices de queimadas são muito elevados principalmente pelo fato de as condições climáticas serem favoráveis à propagação do fogo, em consequência ao longo dos anos o país se tornou líder na América Sul, na utilização deste recurso para diversos fins (KLINK et al., 2005; INPE, 2016).

Dados publicados pelo Instituto de Pesquisa Espacial (INPE) em 2016 mostram que, os números de focos de queima no Brasil aumentaram de uma maneira significativa nos últimos anos, com destaque para alguns Estados, como: Mato Grosso, Tocantins, Maranhão, Pará, Rondônia, Amazonas e Acre (INPE, 2016). Ainda de acordo com Instituto de Pesquisa Espacial (2016), o Estado do Tocantins ocupou a 2a colocação no ranking com 2.737 focos registrados somente no mês de junho de 2016, quebrando o seu recorde mensal, pois pelo histórico desde 1998 a 2015 a maior incidência de focos ocorreu em junho de 2010, com 2.408 
casos. Os biomas brasileiros que mais registraram focos de queimadas em julho/2016 foram o Cerrado, com 8.891, seguido da Amazônia com 6.044 e da Mata Atlântica, com 2.859 focos (INPE, 2016).

Considerando que, no Estado do Tocantins, especialmente no território que corresponde ao Município de Guaraí existem poucos trabalhos realizados a respeito do tema abordados o presente artigo tem por objetivo expressar os resultados qualitativos/quantitativos obtidos em um estudo sobre a influência do fogo na composição físico/química de um tipo de solo em dois pontos de em uma fazenda localizada no Município de Guaraí, Estado do Tocantins.

\section{MATERIAIS E MÉTODOS}

\section{Descrição do Município e da área de coleta}

As amostras de solo foram coletadas no Município de Guaraí, Estado do Tocantins (Figura 1 B-C), que se encontra sob as coordenadas geográficas $08^{\circ} 50^{\prime} 03^{\prime \prime}$ S e $48.30^{\prime} 37^{\prime \prime} \mathrm{W}$, estando a uma altitude de 259 metros a cima do nível do mar, com clima tropical, relevo com características de depressão na maior parte do território, população estimada em 2015 de 25.399 mil habitantes, com área urbana e rural totalizando $2.268,147 \mathrm{~km}^{2}$ (IBGE, 2016).

O clima da região de acordo com o sistema de classificação global de climas, proposto por Köppen (1948), é do tipo aw, caracterizando-se por um clima tropical que apresenta inverno seco (maio a outubro), com chuvas intensas durante o período de verão (novembro a abril). O município tem sua economia fortemente baseada na agricultura e pecuária (IBGE, 2016). O solo é do tipo arenoso que apresentam certa predominância em todo o território do Município.

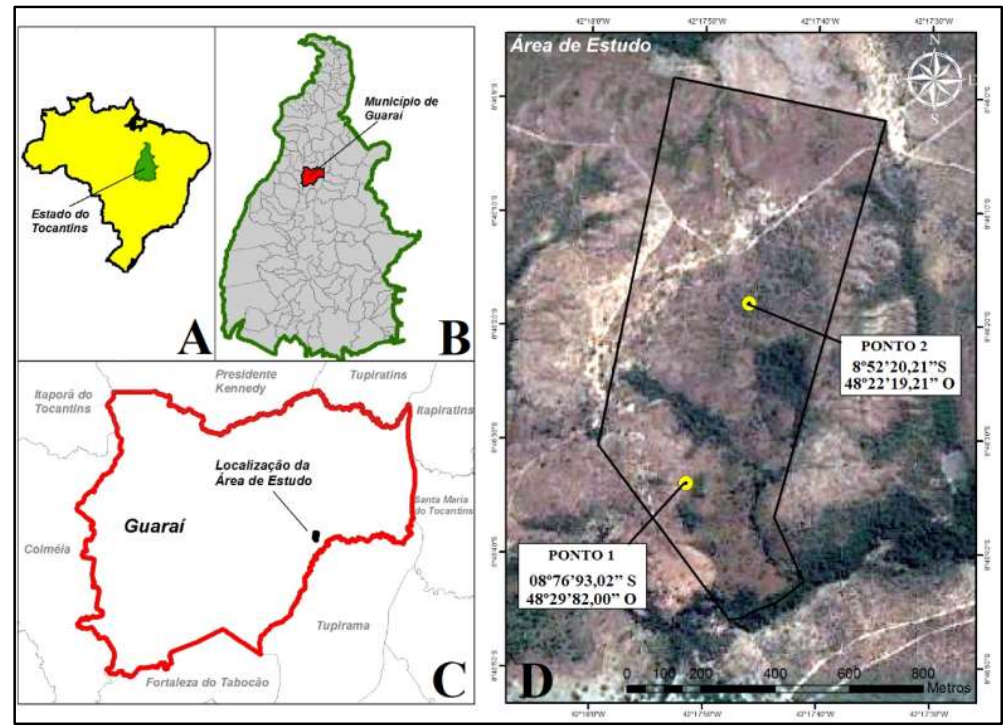

Figura 1: Mapa de localização do Município de Guaraí dentro do Estado do Tocantins. (A) O mapa do Brasil com destaque ao Estado do Tocantins. (B) Estado do Tocantins com destaque ao Município de Guaraí. (C) O Município de Guaraí com destaque a Fazenda José e Mariana e (D) Fazenda José e Mariana com destaque aos dois pontos de coleta.

O estudo foi realizado em uma propriedade particular (Sítio José e Mariana) (Figura 1 D), localizado

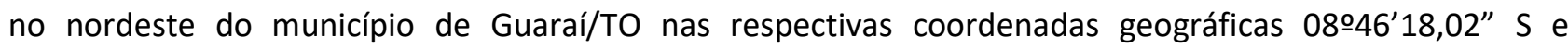
4817'46,39" O. A área de estudo possui um total de 72,70 ha que apresenta uma pequena extensão de área 
queimada com aproximadamente $360 \mathrm{~m}^{2}$, (um dos pontos de coleta) para realizar a limpeza do terreno, sendo que, a maior parte do terreno se apresenta intactas ao fogo. As coletas das amostras de solo foram realizadas em dois pontos desta área, no ponto 1 sob as coordenadas de 08 ำ $76^{\prime} 93,02^{\prime \prime}$ S, 4829'82,00" O e o ponto 2 nas seguintes coordenadas 08ำ'20,21" S e 4822'19,21" O.

\section{Coleta das amostras de solo}

No período de agosto de 2016, foram realizadas coletas de amostras de solos em duas condições extremas (um solo que sofreu queimada e outro que não sofreu queimada) na Fazenda José e Mariana (Figura 2 A e Figura 2 B) a fim de analisar os indicadores químicos, físico de qualidade do solo para verificar quais são os danos que o fogo pode ocasionar a este substrato. Com o auxílio de uma cavadeira, foram perfurados micropoços nos dois tipos de solos nas camadas de 00 e $20 \mathrm{~cm}$ (Figura 2 C e Figura 2 D) e recolhidas amostras da superfície e do fundo dos micropoços.

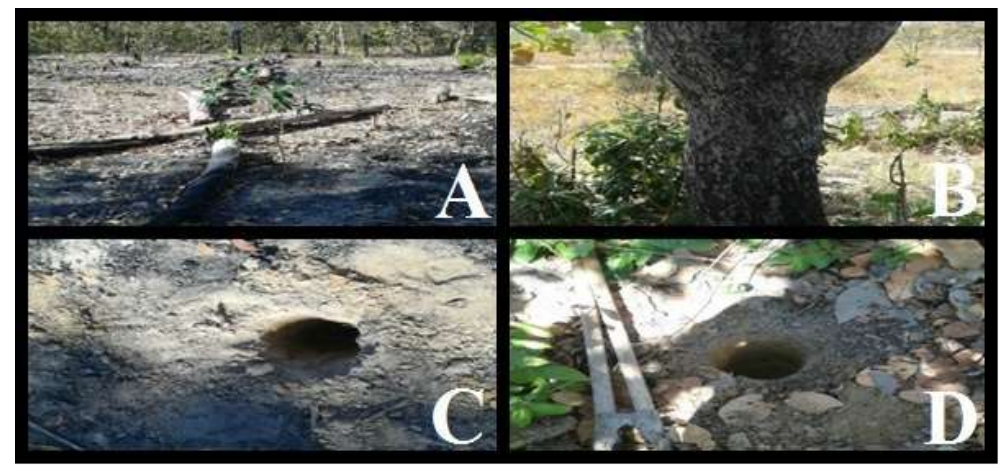

Figura 2: Etapas da coleta das amostras para a realização das análises. (A) Imagem que demonstra a área que sofreu queimada; (B) Imagem da área que não sofreu queimada; (C) Micropoço perfurado na área que sofreu queimada para a coleta de amostras do fundo e (D) Micropoço perfurado na área que não sofreu queimada para a coleta de amostras do fundo.

As amostras foram identificadas pelo código numérico atribuído a cada uma delas, com o nome do pesquisador e nome da propriedade. Estas amostras foram acondicionadas em garrafas do tipo PET até o seu devido processamento. Logo após a coleta estas amostras foram encaminhadas ao laboratório de análise de solos (Safrar análises agrícolas) para a realização das análises físico/químicas destas amostras.

\section{Processamento das amostras}

A metodologia de processamento das amostras seguiu as recomendações do protocolo do método utilizado na Embrapa Solos, publicado em 1998 em um documento denominado 'Análises Químicas para Avaliação da Fertilidade do Solo' com adaptações propostas pelo Programa de Controle de Qualidade das Análises de Solos IAC (2005).

Primeiramente, as amostras foram separadas, para em seguida realizar a secagem das frações do solo, processo esse conhecido como terra fina seca ao ar TFSA (EMBRAPA, 1997). Todo o processamento foi realizado seguindo os padrões de recomendação, com as amostras devidamente identificadas e posteriormente espalhadas em uma folha de papel, os torrões foram destorroados manualmente. Após o destorroamento manual estas amostras passaram pela etapa final de secagem com o auxílio de uma estufa 
com circulação de ar forçado, a 40ㄷ (EMBRAPA, 1997). Em seguida as amostras foram submetidas ao peneiramento, utilizando-se uma peneira com a malha $2 \mathrm{~mm}$, inutilizando alguns resíduos da amostra retida na peneira para o recipiente apropriado, devidamente identificado para a realização das análises físico/químicas.

\section{Análise físico/química das amostras}

As amostras foram então, quebradas em pequenos pedaços para posteriormente serem levadas ao laboratório, as amostras foram devidamente identificadas com o nome do proprietário. No laboratório as amostras passaram pelas peneiras separando os vestígios de matérias primas da terra. Em seguida foram separadas com a ajuda de uma ferramenta conhecida como cachimbo na medida de $10 \mathrm{~cm}$ em um frasco do tipo Erlenmeyer.

$\mathrm{Na}$ outra fase do teste as amostras receberam uma quantidade de $50 \mathrm{ml}$ de uma solução extratora de acordo com o tipo de material, como: cálcio, alumínio e magnésio. Logo após, essas amostras foram colocadas em uma máquina agitadora. Com o movimento dessa agitação a solução extratora é misturada com o solo, conseguindo através desse contato a extração do cálcio, magnésio e alumínio do solo. Após 16 horas de repouso para manter a decantação. Todo esse procedimento de extração de nutrientes das amostras de solos forma realizadas através de extratores que fazem essa identificação, no caso da extração com $\mathrm{KCl} 1 \mathrm{M}$ : obtém cálcio, magnésio e alumínio. $\mathrm{O}$ pH foi aferido com aparelho de pHmetro em água e foi utilizado a Solução padrão de pH 4,00 e 7,00 com diluições conforme orientação do fabricante.

Também foi utilizada a solução extratora de Mehlich1, conhecida por solução duplo-ácida, e é constituída por uma mistura de $\mathrm{HCl0}, 05 \mathrm{M}+\mathrm{H} 2 \mathrm{SO} 4$ 0,0125M. O emprego dessa solução como extratora para análise da quantidade de fósforo, potássio, sódio e micronutrientes do solo se baseia na solubilização desses elementos pelo efeito de $\mathrm{pH}$, entre 2 e 3 , sendo papel do $\mathrm{Cl}$ - o de restringir o processo de reabsorção dos fosfatos recém-extraídos.

Para os micronutrientes a relação do solo: extrato sugerido é de 1:5, enquanto para os demais elementos é de 1:10, a matéria orgânica que foi obtido pelo Método volumétrico com bicromato de potássio. $\mathrm{O}$ carbono da matéria orgânica da amostra foi oxidado a $\mathrm{CO}_{2}$ e o cromo $(\mathrm{Cr})$ da solução extratora foi reduzido da valência $+6(\mathrm{Cr}+6)$ à valência $+3(\mathrm{Cr} 3+)$. Na sequência, fez-se a titulação do excesso de bicromato de potássio pelo sulfato ferroso amoniacal.

\section{RESULTADOS E DISCUSSÃO}

A expressão dos resultados foi realizada de acordo com as informações contidas no laudo de análise (Tabela 1) do solo na área pesquisada, com amostras de solos que foram afetados pelas queimadas e amostras de solo que não foram afetados pelas queimadas, sendo assim no laudo descreve que nas áreas não afetadas pelo fogo não apresentaram resultados significantes na quantidade de macro e de micronutrientes. 
Tabela 1: Resultado dos macros e micronutrientes encontrados nos dois tipos de solos estudados na área queimada e na área não queimada.

\begin{tabular}{|l|l|l|l|l|l|}
\hline Macronutriente & A.Q & A.N.Q & Micronutriente & A.Q & A.N.Q \\
\hline Cálcio (Ca) & 0,7 & 0,7 & Boro (B) & 0,19 & 0,20 \\
\hline Potássio (K) & 33 & 139 & Cobre (Cu) & 0,3 & 0,4 \\
\hline Magnésio (Mg) & 0,3 & 0,3 & Ferro (Fe) & 76 & 43 \\
\hline Enxofre (S) & 7 & 9 & Manganês (Mn) & 0,6 & 1,0 \\
\hline & & & Molibdênio (Mo) & 3,2 & 3,1 \\
\hline & & & Zinco (Zn) & 1,6 & 1,1 \\
\hline
\end{tabular}

\section{*A. Q = Área Queimada; A. N. Q = Área Não Queimada}

De modo geral, os resultados encontrados nos dois tipos de solos não apresentaram diferenças significantes, tanto para macro como para micronutrientes, demonstrando que o fogo não alterou drasticamente a composição química destes dois tipos de solos. Apenas alguns elementos foram encontrados em menor quantidade nos solos queimados, e de contramão, alguns se apresentaram em maior quantidade no solo não queimado, como por exemplo, o Ferro que foi encontrado uma quantidade quase que dobrada no solo queimado.

Em relação aos macronutrientes como o $\mathrm{S}$ no solo que foi afetado pela queimada apresentou a quantidade de $7 \mathrm{dm}^{3}$ um teor considerado médio para este tipo de solo, enquanto que a área não queimada apresentou praticamente o mesmo resultado que a área queimada, com $9 \mathrm{dm}^{3}$.Dois outros macronutrientes que não apresentaram diferença em relação a quantidade na área queimada para a área não queimada foram o Ca e o Mg pois em abas as áreas foram encontrados o mesmo valor destes macronutrientes de $0.7 \mathrm{dm}^{3} \mathrm{e}$ $0,3 \mathrm{dm}^{3}$ respectivamente, os solos arenosos possuem uma quantidade muito baixa de matérias orgânicas o que torna esse tipo de solo desprovidos de enxofre, e sabe-se que as queimadas muito comum no cerrado brasileiro tem agravado ainda mais a deficiência desse macronutriente, o cálcio é importante para o desenvolvimento das raízes e ainda torna as plantas mais resistentes contra as pragas, o magnésio é um macronutriente que auxilia no crescimento das plantas, esse elemento químico é de suma importância por ser encontrado em pequenas quantidades nas maiorias dos solos, e essa deficiência influência nos rendimentos das culturas anuais e perenes (REIN et al., 1999; STIPP et al., 2010).

Quanto aos resultados encontrados para o macronutriente $K$, este apresentou um número significante entre as áreas, demonstrando que o seu valor no solo tem intima relação com a ausência de fogo. $\mathrm{Na}$ área que sofreu queimada, encontrou-se um valor de $33 \mathrm{dm}^{3} \mathrm{de} \mathrm{K}$, enquanto que, na área que não sofreu queimada o valor encontrado de $\mathrm{K}$ foi significantemente, 4 vezes maior, com um $139 \mathrm{dm}^{3}$. De acordo com Raji et al. (1996) os valores encontrados tanto no solo que sofreu queimada como no solo que não sofre queimada não são considerados bons para o plantio de plantas perenes e anuais pois para ser adequado os valores deveriam estar de 13 a $30 \mathrm{dm}^{3}$ e para as plantas perenes e de 16 a $40 \mathrm{dm}^{3}$ para as plantas anuais.

Há diversos estudos que relatam aumentos nas concentrações dos macronutrientes de N, P, K, Ca e Mg com o uso do fogo, colaborando no imediato crescimento das plantas por terem absorvidos os nutrientes presentes nas cinzas, o problema é que os efeitos são a médio prazo, porque com a ação da chuva os nutrientes se perdem no solo fazendo com que a quantidade desses minérios seja encontrada em concentrações menores do que a de solos que não sofreram a ação das queimadas (REDIN et al., 2011). 
Com relação aos micronutrientes também não foram encontrados resultados com diferenças consideradas relevantes entre em ambas as áreas. Com relação ao micronutriente $\mathrm{Cu}$, este apresentou teor de $0,3 \mathrm{dm}^{3}$ no solo queimado e de 0,4 no solo não queimado. Outro micronutriente que não apresentou valores significantes ente os dois tipos de solos, foi o B, pois enquanto que, na área queimada foram encontrados valores de $0,19 \mathrm{dm}^{3}$, na área não queimada foram encontrados $0,20 \mathrm{dm}^{3}$. Outro micronutriente, sem resultados marcantes entre as duas áreas está o Mo, com resultados de $3,2 \mathrm{dm}^{3}$ e $3,1 \mathrm{dm}^{3}$ respectivamente.

Os micronutrientes que apresentaram diferenças singelas entre as duas áreas foram o $\mathrm{Mn}$ e o $\mathrm{Zn}$, sendo que para os valores de $\mathrm{Mn}$ foram encontrados $0,6 \mathrm{dm}^{3}$ no solo que sofreu queimada e $1,0 \mathrm{dm}^{3}$ no solo que não sofreu queimada. Enquanto que, para o Zinco na área queimada o valor encontrado foi maior do que na área que não sofreu queimada, com valores de $1,6 \mathrm{dm}^{3}$ e $1,1 \mathrm{dm}^{3}$ respectivamente.

O micronutriente que apresentou resultados significativos foi o Ferro, os valores encontrados neste trabalho, demonstram que este micronutriente tem forte relação com a presença de fogo para a sua quantidade neste tipo de solo, pois, enquanto que, na área queimada o solo apresentou um valor de $76 \mathrm{dm}^{3}$ na área não queimada este valor foi significantemente inferior, de apenas $43 \mathrm{dm}^{3}$. Os micronutrientes de plantas, os quais abrangem $\mathrm{B}, \mathrm{Cl}, \mathrm{Cu}, \mathrm{Fe}, \mathrm{Mn}, \mathrm{Mo}, \mathrm{Ni}$ e $\mathrm{Zn}$ são requeridos pelas plantas em concentrações muito baixas para o seu adequado crescimento e reprodução (FERREIRA, 2012).

Sendo assim nessas concentrações muito baixas, os micronutrientes são essenciais tanto para o crescimento quanto para o desenvolvimento das plantas e agem como constituintes das paredes celulares, como por exemplo, o micronutriente Boro, e para o desenvolvimento das membranas celulares (B, Zn), como constituintes de enzimas ( $\mathrm{Fe}, \mathrm{Mn}, \mathrm{Cu}, \mathrm{Ni})$, e como ativadores de enzimas $(\mathrm{Mn}, \mathrm{Zn})$ e na fotossíntese $(\mathrm{Fe}, \mathrm{Cu}$, $\mathrm{Mn}, \mathrm{Cl}$ ) (FERREIRA, 2012).

Sabemos que o teor inadequado de micronutrientes nas culturas, que é limitante ao seu crescimento, e que pode passar despercebido, não só tem efeito direto sobre o desenvolvimento da cultura, mas também reduz a eficiência de uso dos fertilizantes contendo macronutrientes (KIRBY et al., 2007). Além disso, os micronutrientes ( $\mathrm{Cu}, \mathrm{Mn}, \mathrm{Zn}, \mathrm{B})$ estão envolvidos na fase reprodutiva do crescimento das plantas e consequentemente na determinação da produtividade e da qualidade da cultura colhida (FERREIRA, 2012). Eles também conferem resistência ( $\mathrm{Mn}, \mathrm{Zn}, \mathrm{Mo}$ ) contra estresses bióticos e abióticos, incluindo pragas e doenças (KIRBY et al., 2007).

No presente trabalho também foram realizados testes para a identificação do tipo de solo trabalhado. A Tabela 2 do presente trabalho mostra os resultados granulométricos e do tipo de solo, sendo que o solo é do tipo arenoso/argiloso com Silte. Estes resultados estiveram muito próximos para as duas áreas trabalhadas, sendo que, no solo que não sofreu queimada foram encontradas $700 \mathrm{G} \mathrm{kg-}^{-1}$ e na área que não sofreu queimada foi de $725 \mathrm{G} \mathrm{kg}^{-1}$. Foram encontrados $238 \mathrm{G} \mathrm{kg}^{-1}$ e $225 \mathrm{G} \mathrm{kg}^{-1}$ respectivamente nos dois tipos de solos. Também foram encontrados $63 \mathrm{G} \mathrm{kg-}^{-1}$ e $50 \mathrm{G} \mathrm{kg-}^{-1}$ de Silte respectivamente. Estes resultados estão de acordo com aqueles encontrados em outro estudo, que trabalhando com solos no Município declararam que o solo típico de Guaraí é do tipo arenoso. 
Tabela 2: Resultados da análise granulométrica dos dois solos trabalhados na presente pesquisa.

\begin{tabular}{|l|l|l|}
\hline Análise Granulométrica & A.Q. & A.N.Q. \\
\hline Argila & 238 & 225 \\
\hline Silte & 62 & 50 \\
\hline Areia Total & 700 & 725 \\
\hline Classificação & Média & Média \\
\hline
\end{tabular}

*A. Q = Área Queimada; A. N. Q = Área Não Queimada

$\mathrm{O}$ presente trabalho realizou teste de $\mathrm{pH}$ do solo. $\mathrm{O} \mathrm{pH}$ da área que sofreu queimadas apresentou o resultado 4,5 uma acidez considerada alta, já a área que não sofreu queimadas foi de 4,6 também alta, os resultados de ambas amostras indicam que o solo está ácido, havendo a necessidade de calcário para que essa acidez do solo seja corrigida a índices que favoreçam a uma maior produtividade da lavoura.

Na tabela 3 do presente trabalho, forma expressos os resultados quanto às classes de fertilidade do solo. De modo geral os dois tipos de solo não apresentaram resultados distantes tanto para aquele que sofreu queimada como para aquele que não sofreu queimada, porém estes solos apresentaram resultados baixos quanto ao seu potencial de fertilização.

Tabela 3: Classes de interpretação de fertilidade do solo para a matéria orgânica e para o complexo de troca catiônica.

\begin{tabular}{|l|l|l|}
\hline Un. de Med. & A.Q & A.N. Q \\
\hline $\mathrm{Al}$ & 0,40 & 0,50 \\
\hline $\mathrm{H}+\mathrm{Al}$ & 3,90 & 3,90 \\
\hline M.O. & 3,2 & 3,1 \\
\hline C.O. & 1,9 & 1,8 \\
\hline
\end{tabular}

*A. Q = Área Queimada; A. N. Q = Área Não Queimada

Os resultados quanto a Acidez Trocável (AL), também não apresentaram resultados distantes nas duas áreas trabalhadas. Os resultados foram de 0,40 e 0,50 cmolc $/ \mathrm{dm}^{3}$ respectivamente. Estes valores não considerados bons para a acidez trocável, pois para que este número fosse considerado um valor considerado bom os solos deveriam ter apresentado valores entre 1,01 a $2 \mathrm{cmolc} / \mathrm{dm}^{3}$.

Os resultados quanto a Acidez Potencial $(\mathrm{H}+\mathrm{Al})$, demonstraram mais uma vez que o fogo não foi capaz de alterar este parâmetro nas duas áreas trabalhadas. Nas duas áreas a Acidez Potencial foi de 3,9 $\mathrm{cmolc} / \mathrm{dm}^{3}$. Estes resultados demonstram que este é mais um parâmetro que interfere na fertilidade do solo, pois um solo para ter condições de fertilidade deve apresentar entre 5,01 a $9 \mathrm{cmolc} / \mathrm{dm}^{3}$.

Quanto à quantidade de Carbono Orgânico (C.O.) presente no solo, a diferença entre os dois tipos de solos foi discreta, enquanto que a área queimada foi encontrada uns resultados $1,9 \mathrm{dag} / \mathrm{kg}$ na área que não sofreu queimada foi de 1,8 dag $/ \mathrm{kg}$. Os dois tipos de solos apresentam quantidades insuficientes de Carbono Orgânico, pois para que um solo tenha uma quantidade considerada boa para o desenvolvimento dos vegetais os seus resultados deveriam estar entre 2,33 a 4,06 dag/ $\mathrm{kg}$.

A quantidade de Matéria Orgânica encontrada nos dois tipos de solos também apresentou resultados muito próximos nas duas áreas trabalhadas. $\mathrm{Na}$ área que sofreu queimada foi encontrado $3,2 \mathrm{dag} / \mathrm{kg}$ enquanto que na área que não sofreu queimada foi de 3,1 dag/ $/ \mathrm{kg}$. Estes valores não são considerados bons para a fertilidade do solo, pois solos para serem considerados férteis é necessário que tenha entre 4,01 a 7 dag/kg (ALVAREZ et al., 1999). 


\section{CONCLUSÕES}

No decorrer da realização deste trabalho pode se notar que o fogo não foi um fator capaz de modificar a composição física e química nas duas áreas trabalhadas, pois os valores de macro e micronutriente, assim como os parâmetros de fertilidade dos solos não apresentaram resultados significantes nas duas áreas. Também não foram expressos resultados de interferência no pH do solo entre estas áreas, pois as duas apresentaram valores próximos e os solos se encontravam extremamente ácidos.

Diante das informações citadas a cima, conclui-se que é necessário realizar novos trabalhos com diferentes tipos de solos para testar a influência do fogo na composição química e física dos solos e chegar a um denominador comum a respeito desta temática, pois o fogo é uma prática utilizada até os dias atuais por pequenos proprietários de terra para fazer o tratamento entre uma safra e outra, sem que tenha conhecimento o suficiente dos benefícios e dos malefícios da adoção desta prática para o solo, principalmente no Cerrado brasileiro.

\section{REFERÊNCIAS}

BRASIL. Plano de ação para prevenção e controle do desmatamento e das queimadas: cerrado. Brasília: MMA, 2011.

EMBRAPA. Empresa Brasileira de Pesquisa Agropecuária. Centro Nacional de Pesquisa de Solos. Manual de métodos de análise de solo. 2 ed. Brasília: EMBRAPA, 1997.

EMBRAPA. Empresa Brasileira de Pesquisa Agropecuária. Análises químicas para avaliação de fertilidade do solo, documento no 3. Brasília: EMBRAPA, 1998.

FERREIRA, M. M. M.. Sintomas de deficiência de macro e micronutrientes de plantas de milho híbrido BRS 1010. Revista Agro@mbiente, v.6,n.1, p.74-83, 2012.

FERNANDES, P. A.; PÊSSOA, V. L. S.. O cerrado e suas atividades impactantes: uma leitura sobre o garimpo, a mineração e a agricultura mecanizada. Observatorium: Revista Eletrônica de Geografia, v.3, n.7, p.19-37, 2011.

IBGE. Instituto Brasileiro de Geografia e Estatística. Senso demográfico 2016. Rio de Janeiro: IBGE, 2016.

INPE. Instituto Nacional de Pesquisas Espaciais. Portal do Monitoramento de Queimadas e Incêndios. São José dos Campos: INPE, 2014.
JIMÉNEZ-CISNEROS, B.. Complexidade: rede e conexões do ser sustentável, um livro para aprender. Kairós, 2014.

KLINK, C. A.; MACHADO, R. B. A.. conservação do Cerrado brasileiro. Rev. Mega Diversidade, v.1, n.1, p.147-155, 2005.

KÖPPEN, W.. Climatologia: Com Estudio de los climas de latierra. México-Buenos Aires: Fondo deCultura Economia, 1948.

REDIN, M.; SANTOS, G. F.; MIGUEL, P.; DENEGA, G. L.; LUPATINI, M.; DONEDA, A.; SOUZA, E. L.. Impactos da queima sobre atributos químicos, físicos e biológicos do solo. Ciência Florestal, v.21, n.2, p.381-392, 2011.

REIN, T. A.; SOUSA, D. M. G.. O magnésio na fertilidade dos solos do cerrado. Brasília: Embrapa Cerrados, 1999.

RHEINHEIMER, D. S.; SANTOS, C. P.; FERNANDES, V. B. B.; MAFRA, A. L.; ALMEIDA, J. A.. Modificações nos atributos químicos de solo sob campo nativo submetido à queima. Ciência Rural, v.33, n.1, p.49-55, 2003.

STIPP, S. R.; CASARIN, V.. A importância do enxofre na agricultura brasileira. Piracicaba: IPNII, 2010.

A CBPC - Companhia Brasileira de Produção Científica (CNPJ: 11.221.422/0001-03) detém os direitos materiais desta publicação. Os direitos referem-se à publicação do trabalho em qualquer parte do mundo, incluindo os direitos às renovações, expansões e disseminações da contribuição, bem como outros direitos subsidiários. Todos os trabalhos publicados eletronicamente poderão posteriormente ser publicados em coletâneas impressas sob coordenação da Sustenere Publishing, da Companhia Brasileira de Produção Científica e seus parceiros autorizados. Os (as) autores (as) preservam os direitos autorais, mas não têm permissão para a publicação da contribuição em outro meio, impresso ou digital, em português ou em tradução. 